Artigo

\title{
Metodologias ativas e tecnologias digitais: propostas pedagógicas para o ensino da matemática
}

\author{
Active Methodologies and Digital Technologies: pedagogical proposals for the teaching of \\ mathematics
}
Metodologías Activas y Tecnologías Digitales: propuestas pedagógicas para la enseñanza de las matemáticas

\author{
João Batista Bottentuit Junior ${ }^{1}$ \\ (iD) [0000-0002-4432-0271]
}

\begin{abstract}
Resumo
Este artigo tem como proposta central discutir sobre as metodologias ativas, apresentando modelos capazes de incentivar o protagonismo nos alunos durante a realização de atividades didáticas em sala de aula na disciplina de matemática. Em paralelo, serão indicadas possíveis tecnologias digitais para cada um dos modelos ativos apresentados. A metodologia utilizada para este artigo foi a revisão bibliográfica, através da qual foram trabalhadas as propostas/modelos ativos de ensino e aprendizagem intitulados de WebQuest e Escape Room em resultados de estudos empíricos disponíveis em bases de dados científicas. Os resultados servirão de exemplos para os estudantes e professores que desejarem adotar estratégias mais alinhadas com os objetivos educacionais atuais na área da matemática.
\end{abstract}

Palavras-chave: Metodologias Ativas. Tecnologias Digitais. Ensino da Matemática. Escape Room. WebQuest.

\begin{abstract}
This article has a central proposal to discuss about active methodologies, presenting models capable of encouraging the protagonism of students during the performance of didactic activities in the classroom in the subject of mathematics. In parallel, possible digital technologies will be indicated for each of the active models presented. The methodology used for this article was the bibliographical review, through which the proposals/active models of teaching and learning entitled WebQuest and Escape Room were worked. The results will serve as examples for students and teachers who wish to adopt strategies that are more in line with current educational goals in the field of mathematics.
\end{abstract}

Keywords: Active Methodologies. Digital Technologies. Teaching Mathematics. Escape Room. WebQuest.

\section{Resumen}

Este artículo tiene como propuesta central discutir sobre metodologías activas, presentando modelos capaces de incentivar el protagonismo de los estudiantes durante la realización de actividades didácticas en el aula en la asignatura de matemáticas. En paralelo, se indicarán las posibles tecnologías digitales para cada uno de los modelos activos presentados. La metodología utilizada para este artículo fue la revisión bibliográfica, a través de la cual se trabajaron las propuestas / modelos activos de

1 joaobbj@gmail.com, Prof. Dr. Doutor em Ciências da Educação (UMINHO), Professor Associado do Departamento de Educação da Universidade Federal do Maranhão - UFMA, São Luís/Maranhão/Brasil. 
enseñanza y aprendizaje titulados WebQuest y Escape Room. Los resultados servirán de ejemplo para estudiantes y profesores que deseen adoptar estrategias más acordes con los objetivos educativos actuales en el campo de las matemáticas.

Palabras claves: Metodologías activas. Tecnologías digitales. Enseñanza de las matemáticas. Escape Room. WebQuest.

\section{Introdução}

A matemática tem sido encarada por muitos estudantes como uma das disciplinas mais difíceis do currículo, pois exige capacidades que envolvem o raciocínio, letramento matemático, interpretação, entre outras habilidades. A Organização para a Cooperação e Desenvolvimento Econômico (OCDE, 2006, p. 18) define 8 (oito) competências transversais que deveriam ser atingidas pelos alunos na disciplina de matemática, quais sejam:
1) compreender as formas características de propor e resolver questões matemáticas;
2) ser capaz de reconhecer, formular e resolver problemas matemáticos;
3) ser capaz de entender, avaliar e construir modelos matemáticos;
4) ser capaz de acompanhar, analisar, avaliar e construir raciocínios matemáticos;
5) ser capaz de lidar com diversas representações de fenômenos matemáticos;
6) ser capaz de manejar os formalismos matemáticos;
7) ser capaz de se comunicar em matemática e sobre seus objetivos; e
8) ser capaz de utilizar as ferramentas apropriadas para a atividade matemática.

Diante das imensas desigualdades na Educação Básica existentes no Brasil, bem como das distâncias geográficas continentais e oportunidades diferenciadas de cada região, são possíveis razões que corroboram para que haja índices negativos em testes realizados em vários níveis de ensino relativamente ao desempenho dos alunos nesta componente curricular.

A matemática já possui um longo histórico de desinteresse, apesar de estar amplamente presente no dia a dia de todo ser humano, uma vez que é possível aplicá-la em diversos campos, desde simples operações básicas até as complexas construções civis (ROTHER, 2016, p. 3).

As causas para o insucesso escolar são diversas, desde a própria base dos alunos da Educação Básica não ser das melhores, até mesmo aspectos relacionados à precária formação de muitos dos professores em diversas instituições de ensino. Porém, antes de achar culpados, é necessário refletir sobre caminhos e soluções que podem ser tomados para melhorar os resultados e colaborar com a aprendizagem dos alunos.

Diversas estratégias podem ser adotadas para facilitar a aprendizagem e atrair a atenção dos alunos, tais como: a utilização de materiais diferenciados em sala de aula, a adoção de metodologias que fogem dos procedimentos didáticos tradicionais, e até mesmo a adoção de tecnologias digitais e simulações em sala de aula. 
Tendo por base a problemática referenciada anteriormente, pode-se mencionar que as metodologias ativas podem constituir-se em possibilidades interessantes para o ensino e aprendizagem da matemática, visto que oferecem aos alunos uma oportunidade de colocar em prática muitos dos conceitos e teorias trabalhadas em sala de aula, já que para muitos deles não há explicação lógica sobre a sua importância ou aplicabilidade no mundo real. Para Macedo et al. (2018, p. 2): "a Metodologia Ativa (MA) tem uma concepção de educação crítico-reflexiva com base em estímulo no processo ensino-aprendizagem, resultando em envolvimento por parte do educando na busca pelo conhecimento".

Neste sentido, os modelos de metodologias ativas podem apresentar-se de maneira muito variada, já que é possível realizar a adaptação curricular de todas elas aos conteúdos que se pretende trabalhar. Alguns exemplos dos modelos ativos utilizados em sala de aula são: Aprendizagem Baseada em Projetos, Aprendizagem Baseada em Problemas, Peer Instruction, Aprendizagem Baseada em Jogos, Gamificação, Metodologia WebQuest, Rotação por Estação, Sala de Aula Invertida, Design Thinking etc.

Apesar dos múltiplos modelos apresentados anteriormente, o presente artigo tem por objetivo central discutir apenas a metodologia WebQuest e o Escape Room Educativo nas aulas de matemática. A metodologia utilizada para este artigo foi a revisão bibliográfica, nela também são apresentados resultados obtidos em estudos empíricos recenseados nas bases de dados científicas. Serão também apresentados alguns recursos tecnológicos digitais que podem ser utilizados em conjunto, assim como experiências em que as referidas metodologias foram utilizadas com resultados positivos.

\section{Metodologias ativas}

Em pleno século $X X I$, não se pode mais pensar em ensino bancário baseado na transmissão de informações, em que os alunos são meros espectadores no processo de suas aprendizagens. Tem-se em vista que o mercado de trabalho exige destes indivíduos características que perpassam pelo domínio de múltiplos conteúdos e habilidades, tendo algumas delas como: raciocínio, cálculo, negociação, comunicação para detalhar fatos e acontecimentos, entre muitas outras. Estas habilidades deveriam estar muito bem solidificadas para que os mesmos tenham melhores condições de atuação na sua vida profissional, ou mesmo nas etapas superiores de seu percurso acadêmico (graduação e pósgraduação). Segundo Rodrigues et al. (2015, p. 2), "a instrução deveria fornecer experiência que as encorajam e que lhes permitam tornarem-se solucionadores de problemas, comunicarem-se e desenvolverem diferentes maneiras de raciocinar matematicamente."

Porém, apesar de toda essa realidade, ainda é comum adentrar em salas de aulas e verificar que os modelos dos anos 50 ainda permanecem vivos. Ou seja, ao longo de uma aula de 60 (sessenta) minutos, apenas o professor se pronuncia, e o aluno passa todo o tempo calado, observando o professor, seus slides e anotações, com pouca ou nenhuma interação ao longo de todo o tempo de aula. Essa metodologia não coaduna com os atuais alunos, tendo em vista que muitos deles têm acesso a recursos variados e tecnologias digitais, bem como perdem a concentração com maior facilidade, necessitando, portanto, de um ensino que possa balancear teoria e prática de forma mais equilibrada. Para Moran (2017, p. 34), "nas metodologias ativas de aprendizagem, o aprendizado ocorre a partir da antecipação, durante o curso, de problemas e situações reais, os mesmos que os alunos vivenciarão depois na vida profissional." 
As metodologias ativas, por outro lado, são todas aquelas em que os alunos se tornam protagonistas do processo, e, deste modo, otimizam o tempo de sala de aula com atividades mais práticas, dinâmicas e interativas, em que a colaboração, o pensamento crítico, a criatividade, a comunicação e a reflexão sobre a prática são sempre colocadas nas pautas das propostas pedagógicas.

O ensino da Matemática deve então, prestar sua contribuição na medida em que forem exploradas metodologias que priorizem a criação de estratégias, a comprovação, a justificativa, a argumentação, o trabalho coletivo, a criatividade, a iniciativa pessoal e a autonomia advinda do desenvolvimento da confiança na própria capacidade de conhecer e enfrentar desafios (BRITO; HAERTEL, 2018, p. 2).

As propostas ativas primam pela construção do conhecimento. Desta forma, as tarefas sempre desafiam os alunos a dar respostas novas ou ainda resolver problemas e enigmas, em que estes modelos atraem mais a atenção deles, pois de outra forma eles logo se distraem e, no fundo, não entendem muito a aplicabilidade do que estão estudando. Além das características acima descritas, envolver os alunos no processo também deverá ser uma preocupação quando as tarefas estão sendo desenhadas, pois, desta forma, eles deverão ser ativos na busca de soluções para problemas reais, bem como o caráter lúdico deverá também fazer parte do processo, a fim de que eles possam produzir melhores resultados, gerando aprendizagens bem mais duradouras.

Além das características acima descritas, outra habilidade bastante presente nas metodologias ativas é a questão da autonomia, em que nela o aluno se torna independente para procurar respostas para suas inquietações, bem como buscar as melhores soluções para os problemas que possam surgir. A autonomia é, sem dúvidas, uma demanda latente atual, uma vez que a vida apresenta a todo momento incógnitas, e estar preparado para resolvê-las será um grande diferencial para cada um dos alunos que assim forem desafiados a desenvolver essa habilidade desde a escola.

Portanto, o professor necessita buscar junto aos alunos quais propostas ativas podem ser mais interessantes para as aulas de matemática. Esta escolha tem a ver com as formas com que os alunos mais gostam de aprender, com a infraestrutura da escola, com o domínio (ou não) de tecnologias digitais, para que se possa planejar e desenhar o melhor modelo para os mesmos. Conforme foi referido na introdução deste artigo, existem muitos modelos a serem adotados na sala de aula ativa, e eles podem perfeitamente ser adaptados aos conteúdos de matemática, no entanto, neste artigo dar-se-á ênfase a duas possibilidades: a WebQuest e o Escape Room.

\section{Metodologia WebQuest}

A WebQuest é uma estratégia ativa que surgiu em 1995, na Universidade de San Diego na Califórnia, tendo como mentores os professores Bernard Dodge e Tom March. Nela, os alunos são desafiados a realizar, por meio de uma pesquisa orientada, uma tarefa. A tarefa é sempre construtiva e colaborativa, de maneira que os alunos possam aplicar os conhecimentos aprendidos por meio da pesquisa realizada, o que geralmente atrai bastante a atenção dos alunos por seu caráter lúdico e construtivo (ABAR; BARBOSA, 2008). 
Silva (2006, p. 44) afirma que "as WebQuests têm a virtude da simplicidade e são ricas para dimensionar os usos educacionais da Internet, com fundamento em aprendizagem colaborativa e processos investigação na construção do saber". Assim, "As WebQuests permitem com que os professores possam utilizar a Internet com criatividade e consciência. A estratégia funciona como uma investigação orientada, na qual algumas ou todas as informações com as quais os aprendizes interagem são originadas de recursos da Internet" (DODGE, 1995, s/p). Porém, não implica dizer que os alunos encontrarão as respostas para as suas tarefas na Internet, mas a pesquisa orientada ajudará na construção dos conhecimentos necessários para a execução da tarefa em grupo.

A metodologia WebQuest, também conhecida como "aventura na web", é composta de 6 (seis) etapas (componentes), sendo a primeira delas a "introdução", onde é apresentada a narrativa inicial que tem sempre uma questão-problema de partida, ou seja, o (a) personagem principal está passando por alguma situação complicada, e pede ajuda aos alunos para que possam, em colaboração, solucioná-la.

A segunda componente é a "tarefa", onde os alunos são desafiados com os seus colegas a resolverem uma questão-problema (resolver um mistério, formular uma teoria, criar uma mensagem persuasiva, escrever uma reportagem); no entanto, ela não poderá ser direta, devendo sempre primar pela descoberta e produção de novos saberes, atingindo altos níveis do domínio cognitivo do aluno. De acordo com Bottentuit Junior e Coutinho (2012, p. 74):

Para ser uma verdadeira WebQuest a atividade deveria incluir tarefas que solicitassem a transformação da informação pesquisada e recolhida num novo produto ou numa nova informação que refletisse a capacidade dos alunos criarem novos saberes.

A próxima componente é o "processo", em que lá são explicados, de maneira detalhada, como a atividade deverá ser realizada. Assim, em cada fase (aula) os alunos sabem exatamente o que precisam realizar, tendo como norte documentos, sites, vídeos e materiais que já foram previamente selecionados pelo professor, numa espécie de curadoria digital em busca dos melhores recursos, que vão garantir a base conceitual e tácita para que os alunos possam desenvolver a sua tarefa.

A seguir tem-se a componente "avaliação", na qual são estabelecidos os objetivos educacionais a serem atingidos, com os seus respectivos pontos/pesos/percentuais, caso atinjam tal competência esperada. Entre os aspectos possíveis a serem avaliados, citam-se: apresentação oral, apresentação em Power Point, produtos criativos, colaboração, produtos escritos, completude das tarefas etc. (CARVALHO, 2002). A avaliação também pode ser compreendida como uma espécie de rubrica, com os seus objetivos e valores muito bem descritos, pois assim o aluno saberá desde o início quais as suas metas, e como deverá direcionar o seu comportamento individual e em grupo, a fim de atingi-lo.

Como última componente da WebQuest tem-se a "conclusão", onde é oferecido um desfecho da história (narrativa), apresentando as vantagens de ter realizado a tarefa e ainda apontando pistas para a investigação futura. Em forma de resumo, a Figura 1 aponta um resumo das componentes e suas respectivas explicações sobre cada uma. 
Figura 1 - Componentes que constituem uma WebQuest.

\section{Componentes da WebQuest}

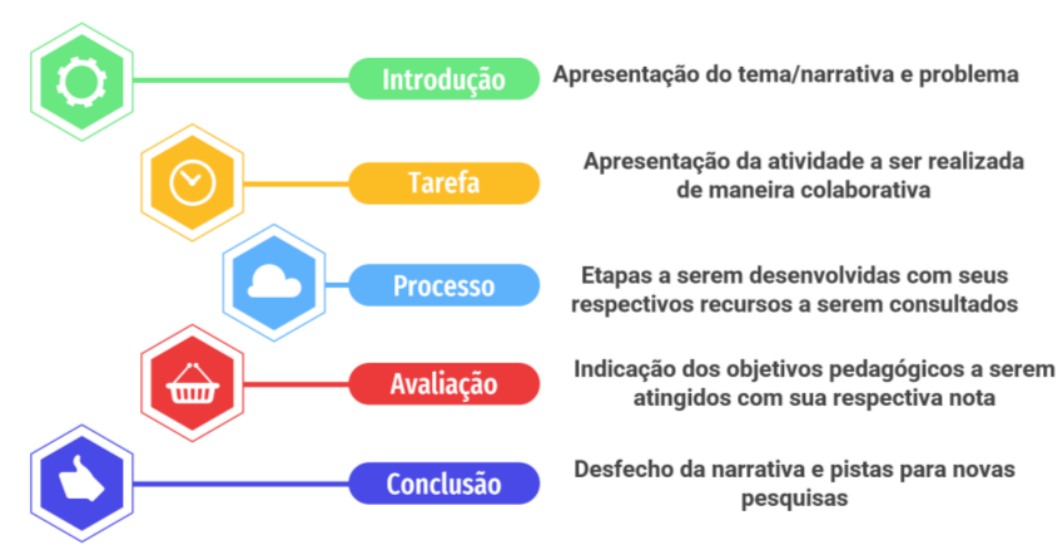

Fonte: Bottentuit Junior (2010).

Ao realizar uma WebQuest, os alunos desenvolvem de maneira colaborativa uma tarefa real, criativa e dinâmica, onde a construção do conhecimento acontece de forma autônoma, e a internet é apenas um auxílio para o desenvolvimento e execução da tarefa no qual eles são desafiados. As disciplinas de Ciências e Matemática são as que mais se encontram recursos baseados em WebQuest na Internet. Num estudo realizado por Bottentuit Junior (2010), foi identificado que essas áreas são mais escolhidas pelos professores para essa estratégia didática, devido às possibilidades mais práticas destas componentes curriculares.

Para desenvolver uma WebQuest, o professor deverá ter em conta que as atividades podem ser empreendidas em qualquer nível de ensino, podendo ter duração breve (uma a três aulas), como também atividades mais duradouras (uma semana, quinze dias e até um mês, ou mais), mas tudo dependerá da complexidade da tarefa proposta. Em relação ao suporte em que as WebQuests são disponibilizadas, elas podem estar em um site, blog, ambiente virtual, até mesmo num slide ou página do Word. O importante é que os alunos tenham acesso aos links para consultar as páginas, vídeos e materiais digitais (pesquisa orientada) indicados pelos professores.

$\mathrm{Na}$ internet existem vários modelos prontos de WebQuests, desta forma, o professor poderá encontrar uma e utilizar com sua turma ou desenvolver uma nova estratégia com base em seu conteúdo e experiência didática. Antes de tudo, é necessário compreender bem a filosofia da WebQuest, compreendendo que não se trata de uma atividade elementar de buscar informação na rede, mas, sobretudo, uma atividade em que os alunos, de maneira colaborativa, se apropriam do conhecimento por meio da pesquisa orientada, para que desta forma possam criar produtos e soluções para diversos problemas que thes forem apresentados. A seguir, são apresentados duas WebQuests disponíveis na Internet para livre consulta e utilização:

- WebQuest EDO, Equações Diferenciais Ordinárias: nesta atividade os alunos são desafiados a aprender mais sobre investimentos financeiros, conforme pode-se observar na Figura 2. 
Figura 2 - Algumas Componentes da WebQuest EDO.

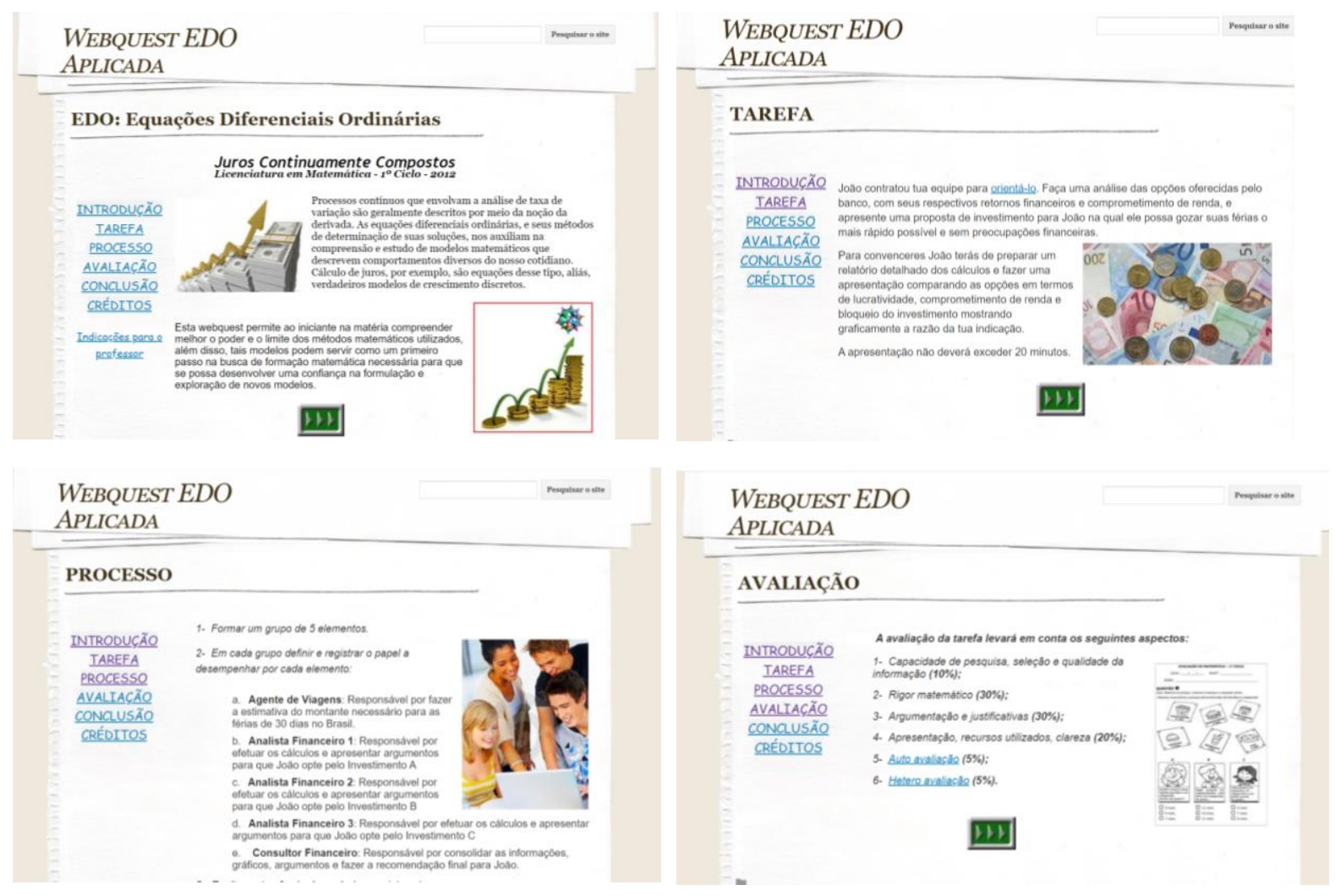

Fonte: WebQues EDO Aplicada (2012, n. p.).

- WebQuest Estatística - nesta atividade os alunos são desafiados a aprender mais sobre uma pesquisa de opinião, onde devem recolher dados para o cálculo estatístico dos dados, como segue na Figura 3, a seguir.

Figura 3 - Algumas Componentes da WebQuest Estatística.
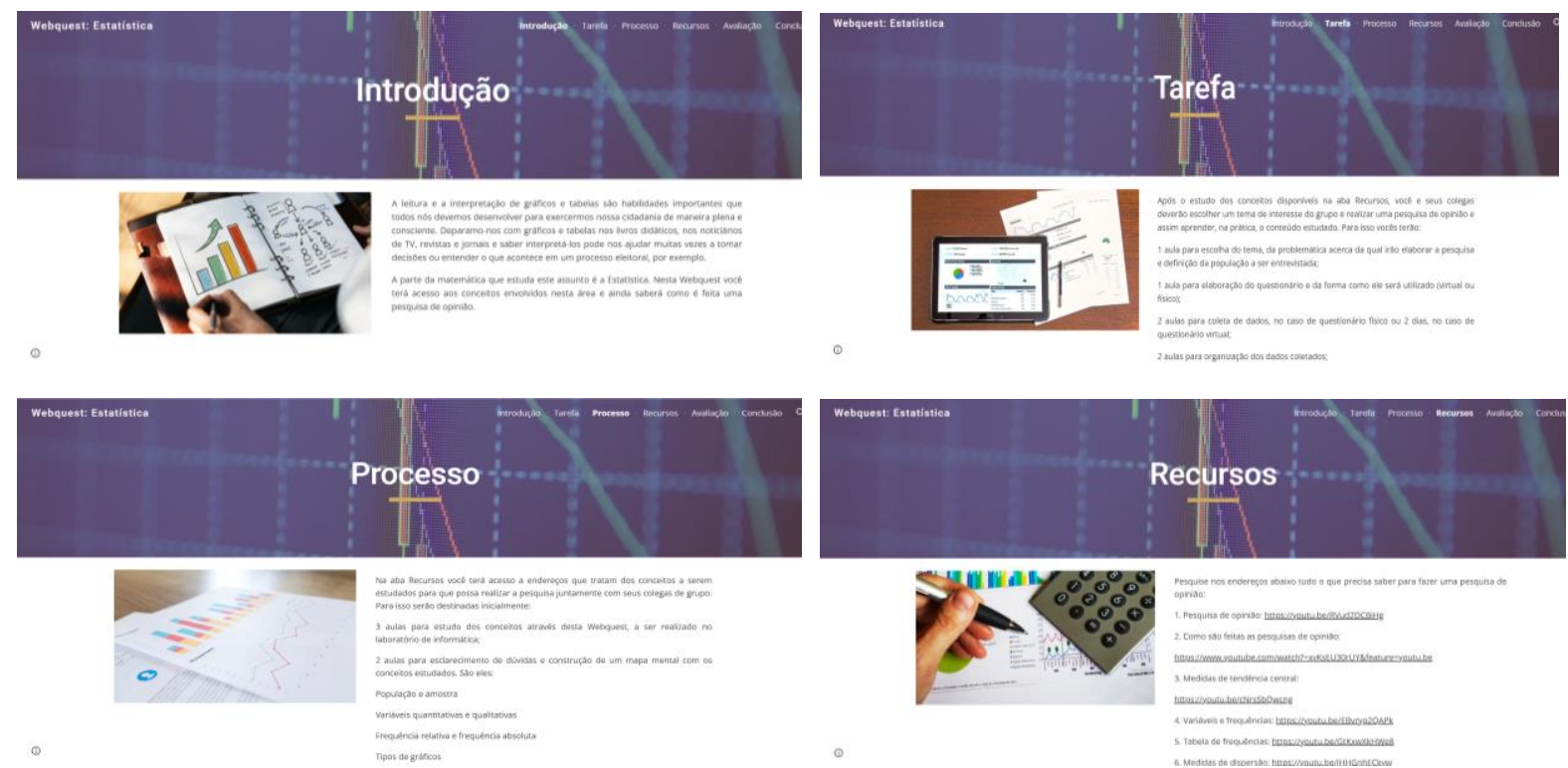
Fonte: WebQuest Estatística [201-].

A cada dia cresce o número de produções disponíveis na internet, desde exemplos de WebQuests que podem ser acessadas e reutilizadas, até mesmo artigos, monografias, dissertações e teses que exploraram a matemática como área de estudo. Passa-se agora a apresentar algumas produções disponíveis nas bases de dados que envolvem a utilização empírica da Metodologia WebQuest em aulas de matemática.

Turci (2015), em sua dissertação de mestrado, elaborou a WebQuest intitulada "BMW Vermelha", na qual explorou a componente curricular da matemática com o tema porcentagem. A experiência foi dinamizada com duas turmas de 90 ano do Ensino Fundamental, e segundo o autor, a experiência foi bastante significativa, uma vez que observou uma maior motivação para a aprendizagem dos conteúdos de matemática, além das potencialidades associadas à revisão dos conteúdos, além de uma nova maneira interdisciplinar de apresentar significados dos assuntos trabalhados de uma maneira prática e real.

Ribacionka (2010), na sua dissertação de mestrado, utilizou a metodologia WebQuest com alunos da 3a Série do Ensino Médio, na modalidade de Educação de Jovens e Adultos (EJA) da Rede Estadual de Educação Paulista. Para a realização da experiência, foi elaborada uma WebQuest intitulada "Conhecendo a Região Onde Você Vive", na disciplina de matemática com o conteúdo de estatística, em que as temáticas foram associadas ao Exame Nacional para Certificação de Competências de Jovens e Adultos (ENCCEJA). Segundo a autora, dada a situação de os alunos da EJA na maioria já serem adultos, e com uma perspectiva mais prática e vivencial acerca dos conteúdos que estudam, eles consideram a proposta da WebQuest bastante interessante, se envolveram na construção da resposta da tarefa proposta, desenvolveram autonomia e a capacidade de trabalho em grupo.

Guimarães (2005), em sua dissertação de mestrado em educação, utilizou a WebQuest intitulada "Polinômios", de curta duração, e foi aplicada com dois grupos de alunos do 8o ano de escolaridade. O conteúdo da matemática trabalhado com os alunos foi sobre os Polinômios. De acordo com a autora, foram utilizados diferentes instrumentos de coleta de dados para aferir a opinião dos sujeitos relativamente à experiência com a WebQuest, onde ela foi bastante útil para melhorarem o entendimento do assunto estudado pelos alunos e a organização de suas ideias.

O número de experiências didáticas com a metodologia WebQuest, que combinam conteúdos da disciplina de matemática, são de fácil localização nas bases de dados, onde além das experiências anteriormente descritas, tem-se ainda muitas outras, tais como: os estudos implementados por Costa (2008), Cruz (2006), Fernandes (2008), Quadros (2005), Sampaio (2006), Santiago (2008), Viseu (2014) e Xavier (2007). Todos eles no âmbito de conteúdos da matemática, e com resultados expressivos e significativos na aprendizagem dos alunos.

Com a parceria das tecnologias digitais, o professor poderá enriquecer bastante a experiência em sala de aula, permitindo uma melhor comunicação entre as equipes, bem como abrindo espaço para a criação colaborativa de produtos e respostas para as tarefas que são solicitadas. Entre esses recursos digitais pode-se indicar as descritas na Tabela 1, a seguir: 
Tabela 1 - Recursos digitais para dinamizar as WebQuests.

\begin{tabular}{|c|c|}
\hline Objetivos & Recursos Digitais \\
\hline $\begin{array}{l}\text { Avaliar a aprendizagem, dinamizar diagnósticos por } \\
\text { meio de quis; }\end{array}$ & Kahoot, Quizizz, Socrative etc. \\
\hline $\begin{array}{l}\text { Criação de portfólios e possibilitar a escrita } \\
\text { colaborativa; }\end{array}$ & Padlet, Blogger, Google Docs etc. \\
\hline Interação entre os participantes; & Nearpod, Wooclap, Mentimeter etc. \\
\hline $\begin{array}{l}\text { Desenvolvimento da competência oral - Criação de } \\
\text { Podcasts; }\end{array}$ & Vocaroo, Anchor, Podomatic etc. \\
\hline Desenvolvimento de mapas conceituais; & Cmaptool, Tex2MindMap, Bubbl.us etc. \\
\hline Desenvolvimento de Vídeos Digitais; & Loom, Screncastfy, CamStudio, Power Point etc. \\
\hline $\begin{array}{l}\text { Apresentações de alto impacto, por meio de } \\
\text { templates prontos. }\end{array}$ & $\begin{array}{l}\text { Slides Go, Slides Carnival, Canva, Prezi, Pown Toow } \\
\text { etc. }\end{array}$ \\
\hline
\end{tabular}

Fonte: Autor.

Além das tarefas realizadas em conjunto com a metodologia WebQuest, é interessante integrar as tecnologias digitais ao processo, ou seja, explorar os recursos de maneira criativa, colaborativa e inteligente, sempre com o intuito de desenvolver altos níveis do domínio cognitivo (síntese, avaliação e criação). Utilizar as tecnologias sem objetivos bem definidos é de fato uma perda de tempo, uma vez que os alunos não se desenvolvem como o esperado.

Com a tecnologia, o professor poderá planejar atividades de pesquisa da informação, interação direta (troca de informações em tempo real), atividades avaliativas (tanto na perspectiva quantitativa como na qualitativa), construção de portfólios digitais, jogos digitais, automatização de processos, visitas virtuais, simulação, realidade virtual, planejamento, programação, organização, desenho etc. São infinitas as potencialidades, e de uma riqueza incrível para o desenvolvimento dos alunos. Portanto, destacaram-se na Tabela 1 alguns recursos digitais que podem auxiliar o professor a aliar as WebQuests às tecnologias educacionais, de acordo com os seus objetivos, assim como as tecnologias podem ainda auxiliar os alunos na execução/construção de seus produtos/tarefas.

\section{Metodologia Escape Room Educativo}

O Escape Room Educativo é uma estratégia de ensino ativa que combina as mecânicas de jogos com os objetivos educacionais que se pretende atingir, e os alunos, de maneira colaborativa, são desafiados a emergir em diferentes cenários (uma delegacia, um castelo abandonado, um hospital, um navio misterioso etc.), para cumprir missões estratégicas que possam, desta forma, ajudá-los a desvendar códigos secretos que farão com que vençam a situação-problema em que foram colocados, e, por fim, possam cumprir a missão. Neste tipo de atividade os alunos necessitam exercitar sua criatividade, capacidade de trabalho em equipe, comunicação e pensamento ágil e, principalmente, dominar o conteúdo para dar as respostas acertadas a cada um dos enigmas elaborados pelo professor.

O Escape Room Educativo surge primeiro no mundo do entretenimento e passa a ser adotado na educação, com as devidas adaptações aos conteúdos curriculares. Consiste em fechar um grupo de jogadores num espaço, no qual terão de resolver um conjunto diversificado de enigmas, tendo como tempo limite 60 minutos para escapar e quase sempre em torno de uma narrativa condutora (MOURA; SANTOS, 2020, p. 108). 
O Escape Room tem sido adotado na educação com diferentes finalidades, tais como: a promoção de um maior engajamento dos alunos, em atividades de exploração do espaço escolar/instituição de ensino, para aumentar a preparação dos mesmos para testes e exames; para incentivar a pesquisa e exploração de novos conteúdos; incentivo à autonomia na busca de informações; desenvolvimento de trabalho e aprendizagem em equipe; exercício da liderança; habilidades de design; além do desenvolvimento de outras habilidades genéricas (VELDKAMP et al., 2020).

Pelo caráter lúdico e ativo, como recurso às atividades, regras e enigmas, o Escape Room é interpretado como um jogo, podendo combinar artefatos físicos e digitais para atingir a aprendizagem, tal como define Rezende, Martins e Oliveira (2020, p. 106):

O Escape Room é um jogo em que a plataforma se desenvolve num contexto real, podendo ter interfaces digitais, além de ser caracterizado como um jogo de ação, pelo fato dos jogadores estarem imersos na resolução de enigmas e/ou desafios num determinado tempo, com a intencionalidade de sair da sala onde se passa o jogo.

Desta forma, para que se possa desenvolver uma atividade do tipo Escape Room, é necessário atentar para alguns passos ou etapas que se pode seguir, a fim de oferecer aos alunos a melhor estratégia possível. Para Moura e Santos (2020, p. 109) deve-se:

1. Pensar na narrativa que deve remeter para o(s) tema(s) curricular(es).

2. Escolher o(s) espaço(s) adequado(s) ao número de participantes.

3. Criar um vídeo introdutório para despertar a curiosidade e introduzir a narrativa.

4. Desenhar as provas e os desafios que devem ser atrativos, surpreendentes e desafiadores. Estes devem ter em atenção os objetivos pedagógicos e o público-alvo.

5. Estabelecer as regras de participação (ajudas, dispositivos a usar, ...), o tempo (cronômetro digital ou analógico) e a formação de grupos. As instruções devem ser claras.

6. Explorar ferramentas digitais e analógicas que se adaptem ao(s) tema(s), à narrativa e aos desafios.

7. Preparar o guia que pode ser digital ou em papel.

8. Concretizar a experiência imersiva de aprendizagem.

A estratégia metodológica do Escape Room Educativo vem sendo adotada por diferentes professores e pesquisadores, tanto no Brasil quanto em outros países, como Europa e Estados Unidos. Ao analisar os trabalhos, percebe-se que os autores têm perspectivas diferentes quanto à adoção da estratégia, porém, alguns pontos são comuns para todos eles, tais como: a elaboração de uma boa narrativa; o estabelecimento de desafios; além dos objetivos de aprendizagem que devem ser contemplados na tarefa. A seguir, pode-se compreender a perspectiva de Segura-Robles e Parra-González (2019), em que de acordo com os autores, uma experiência de Escape Room deverá contemplar os seguintes elementos (ver Figura 4): 
Figura 4 - Elementos que compõem uma experiência de Escape Room.

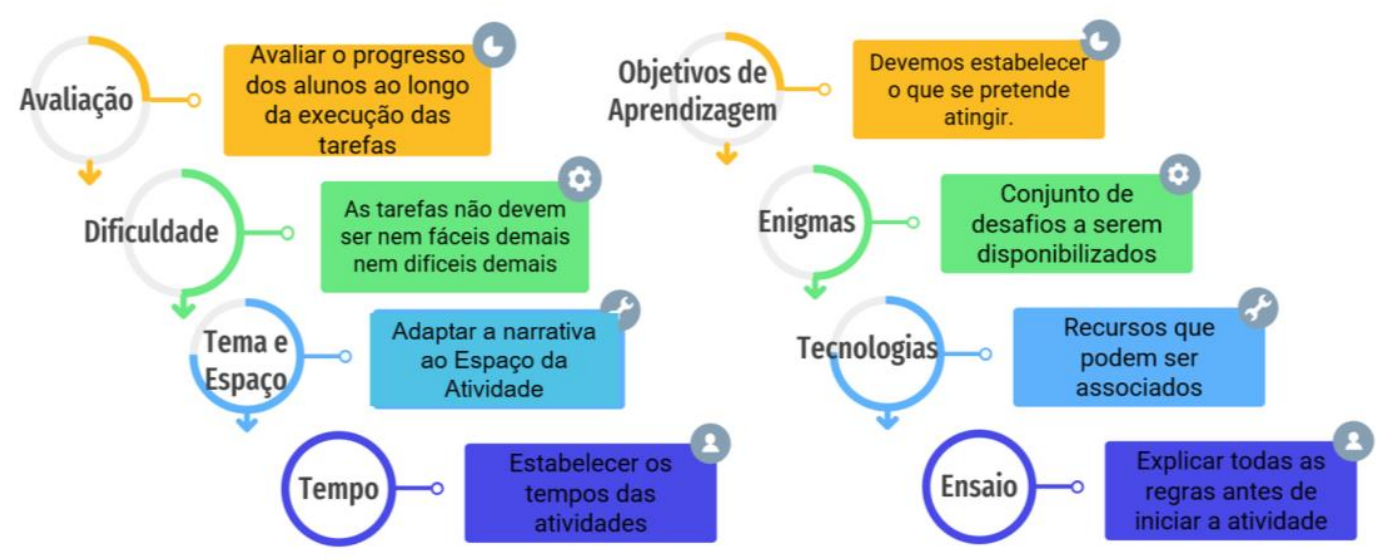

Fonte: Adaptado de Segura-Robles e Parra-González (2019).

Em relação à Metodologia do Escape Room Educativo, ainda não há um número considerável de publicações nas bases de dados voltados especificamente para o ensino da matemática. Em língua portuguesa é possível identificar alguns estudos mais teóricos, e algumas experiências em comunicações em periódicos e eventos científicos; já os trabalhos de dissertação de mestrado e teses, ainda são escassos em comparação com as produções em língua estrangeira. A seguir, apresentam-se algumas das produções recenseadas que envolvem a adoção da estratégia em diferentes áreas.

Sierra Daza e Fernandez-Sánchez (2019) apresentam uma experiência na Universidade de Extremadura com a metodologia Escape Room mediada por tecnologias móveis, com 60 estudantes do primeiro ano do curso de Educação Social. Para a execução da experiência, foram desenvolvidas quatro pistas que os alunos tiveram que desenvolver em grupos de trabalho. Após as experiências, os autores revelaram que os alunos afirmaram sentimentos como: alegria, prazer, diversão e motivação nas aulas. Além disso, no âmbito do trabalho em grupo, foi possível destacar um maior companheirismo e a promoção de habilidades comunicativas.

Aiub (2020), na sua dissertação de mestrado em Ensino de Ciências e Matemática, realizou uma experiência por meio do Escape Room no ensino de matemática. A amostra foi composta por 21 estudantes de uma turma de licenciatura em matemática, de uma instituição pública do estado de São Paulo. De acordo com a autora, os dados coletados na pesquisa indicam que a pesquisa promoveu uma boa experiência de formação inicial desses docentes que participaram de maneira significativa. Além disso, simularam as dificuldades mais eminentes que eles poderão encontrar na sua prática pedagógica diária. Por fim, a realização do estudo permitiu prepará-los de forma mais abrangente para o uso de tais atividades.

Claudio, Machancoses e Piqueras (2019) realizaram um estudo para verificar os benefícios da metodologia Escape Room na educação. Para a realização do estudo, foi elaborada a narrativa intitulada "O estranho desaparecimento de Don José", em que a atividade se enquadra em um contexto educacional específico, e se desenvolve sob o pretexto de revisar os conteúdos matemáticos do 6ㅇa ano do Ensino Fundamental. Além disso, a experiência também teve como objetivo verificar as competências sociais e emocionais dos alunos. Após a realização dos estudos, os autores apontam uma maior integração dos alunos 
nas atividades colaborativas, um maior desenvolvimento das suas competências digitais e maior grau de coesão do grupo na experiência.

Otemaier et al. (2020) realizaram um estudo com alunos do ensino superior na disciplina de Lógica Matemática nos cursos de Engenharia de Software e Sistemas de Informação. Uma das principais metas das estratégias elaboradas foi o exercício do raciocínio lógico, tendo em vista que este é uma das exigências para os indivíduos do século XXI. Os resultados obtidos, conforme os autores, geram impactos positivos no comprometimento, motivação e mobilização da aprendizagem na disciplina de Lógica Matemática. Os dados ainda apontam que os alunos preferem essas atividades a sessões de exercícios tradicionais em sala de aula.

Além das experiências anteriormente descritas, ainda se destacam os estudos de Stohlmann (2020), Ferreira Junior (2019), Monteiro Junior e Reis (2020) e Jiménez et al. (2000), que demonstram resultados positivos na implementação de Escape Room Educativo com diferentes conteúdos de matemática.

Após elaboradas as estratégias, desenvolvidos os enigmas, regras e demais aspectos a explorar no Escape Room, faz-se necessário definir qual suporte será utilizado para a disponibilização da metodologia, ou seja, se será o meio físico ou o digital. Muitos professores optam pelo formato digital, dadas as facilidades que as ferramentas oferecem hoje em dia. No site intitulado "Rede: Laboratório Sustentável de Matemática", o autor disponibiliza um passo a passo de como elaborar um Escape Room de matemática utilizando o Google Forms como plataforma.

Figura 5 - Layout do "Rede Laboratório Sustentável de Matemática".
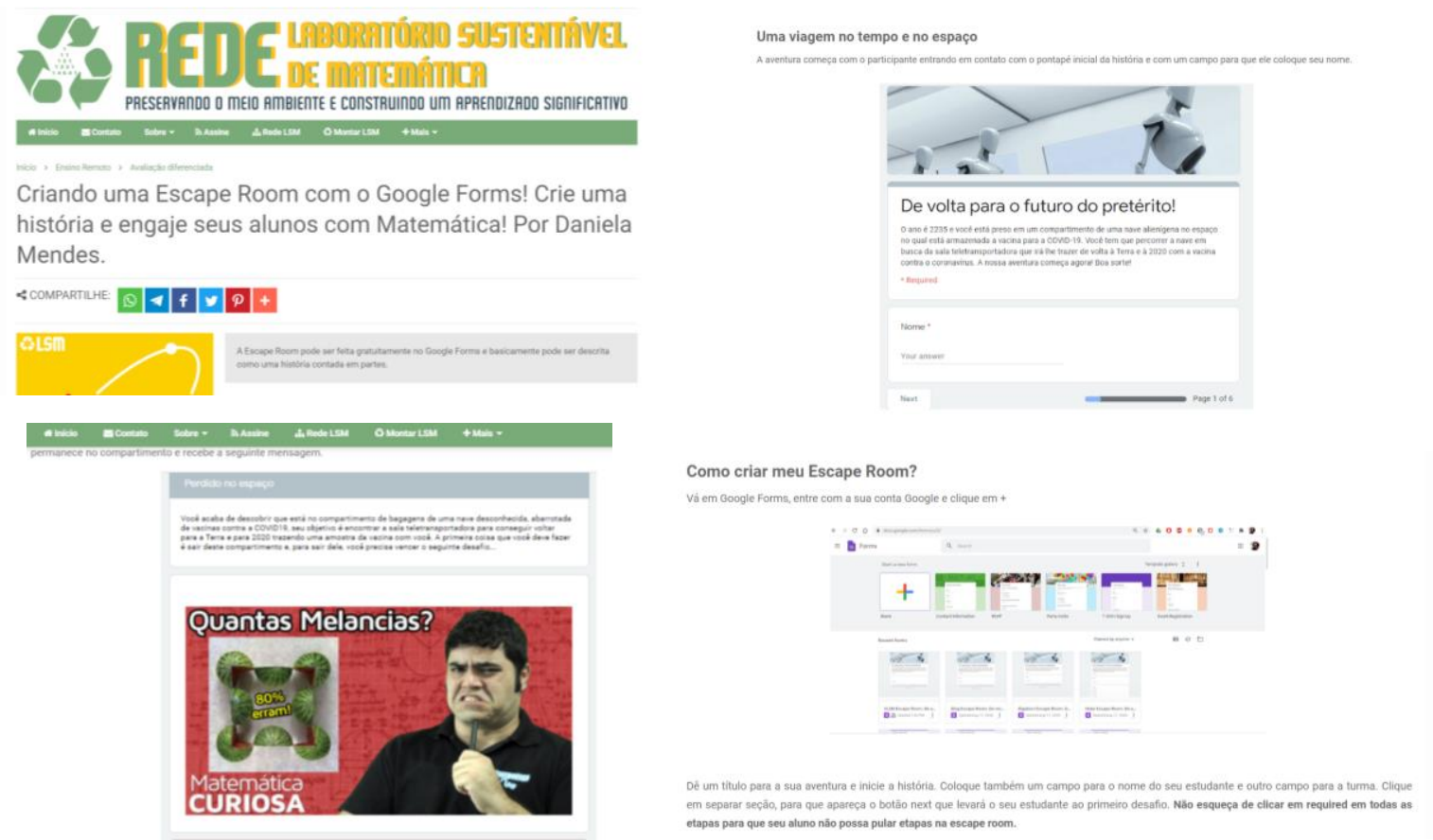

Fonte: Mendes [201-].

Caso seja de interesse do professor, integrar as tecnologias digitais ao processo, elas podem oferecer uma melhor experiência à estratégia deixando-a mais interessante à medida 
em que elas permitem a criação de: cadeados, cartas digitais surpresa, conteúdos interativos, textos animados, nuvens de palavras e muito mais, tornando ainda mais criativas as propostas dos professores. A seguir são apresentados alguns recursos que podem ser associados à criação da estratégia de Escape Room (ver Tabela 2):

Tabela 2: Recursos digitais para dinamizar o Escape Room.

\begin{tabular}{|c|c|}
\hline Objetivos & Recursos Digitais \\
\hline $\begin{array}{l}\text { Criação de questionários e ambientes de recolha de } \\
\text { dados; }\end{array}$ & Google Forms, Survey Monkey, Edupulses etc. \\
\hline $\begin{array}{l}\text { Criação de conteúdos Interativos (imagens, postagens } \\
\text { para redes sociais, apresentações, infográficos etc.); }\end{array}$ & Genially, Canva etc. \\
\hline Criação de vídeos e perguntas interativas; & Playposit, Edpuzzle etc. \\
\hline Criação de jornais on-line; & www.fodey.com/ \\
\hline Criação de nuvens de palavras; & Wordclouds, Tagul, Word Clouds for Kids etc. \\
\hline Criação de jogos e atividades dinâmicas; & Wordwall, Educaplay etc. \\
\hline Criação de palavras cruzadas; & $\begin{array}{l}\text { www.educolorir.com/ } \\
\text { crosswordgenerator.php } \\
\text { criadordecruzadinhas.com.br/ }\end{array}$ \\
\hline Utilização de calculadoras on-line; & $\begin{array}{l}\text { www.calculadora-online.xyz/ } \\
\text { www.matematica.pt/util/ } \\
\text { calculadora-cientifica.php }\end{array}$ \\
\hline Utilização de temporizador on-line. & $\begin{array}{l}\text { relogioonline.com.br } \\
\text { /temporizador/ }\end{array}$ \\
\hline
\end{tabular}

Fonte: Autor.

Com os recursos e objetivos educacionais acima descritos, aliados à criatividade, é possível desenhar diversos enigmas que podem atrair a curiosidade dos alunos, e despertar o interesse pelo estudo de matemática, possibilitando, desta forma, que os resultados deste importante componente curricular possam ser a cada dia melhores.

\section{Considerações finais}

A adoção de qualquer que seja a metodologia ativa no contexto de sala de aula, deve ser sempre alvo de planejamento e uso consciente, pois pode-se transformar facilmente um modelo bem-sucedido em resultados negativos, caso não seja adotada da forma correta. A escolha do recurso digital e do modelo deverá sempre primar pelo desenvolvimento das habilidades necessárias para os estudantes da atual sociedade, tendo em vista que hoje atualmente existe uma variedade incrível de recursos, e o professor poderá implementar modelos e atividades cada vez mais atrativas e envolventes para os alunos, tornando a aprendizagem lúdica e mais leve.

Tanto a Metodologia WebQuest quanto o Escape Room, foram as estratégias mais discutidas neste artigo, e pretendem ativar/melhorar as habilidades e comportamentos importantes para o desenvolvimento pessoal e profissional dos alunos, tais como: a aprendizagem por tentativa e erro, o uso de tecnologias digitais de informação e comunicação em sala de aula, o estímulo ao trabalho colaborativo, a exploração de conteúdos por meio da pesquisa, a autonomia com atividades ativas, a vivência de papéis e personagens diferenciados etc. 
Tendo em vista que a combinação de metodologias ativas com as tecnologias digitais possibilita muitas experiências, é possível planejar WebQuests e atividades de Escape Room que trabalhem conteúdos complexos ou com altos índices de notas baixas. Desta forma, a tecnologia digital poderá ser uma aliada na gestão e organização das atividades, assim como possibilitar a pesquisa e a interação de maneira mais ágil e facilitada. A adoção de metodologias que fogem do tradicional, quando bem planejadas e organizadas, podem permitir um maior envolvimento dos alunos nas aulas e atividades.

\section{Referências}

ABAR, Celina A. A. P.; BARBOSA, Lisbete Madsen. WebQuest, um desafio para o professor: uma solução inteligente para o uso da Internet. São Paulo: Avercamp, 2008.

AIUB, Mariana Maria Rodrigues. Gamificação no ensino de matemática com jogos de "Escape Room" e RPG: percepções sobre suas contribuições e dificuldades. 2020. Dissertação (Mestrado em Ensino de Ciências e Matemática) - Universidade Estadual de Campinas, Instituto de Física Gleb Wataghin, Campinas, SP., 2020. 147p.

BOTTENTUIT JUNIOR, João Batista. Concepção, Avaliação e Dinamização de um Portal Educacional de WebQuests em Língua Portuguesa. 2010. Tese (Doutorado em ciências da educação) - Instituto de Educação, Universidade do Minho, Braga, 2010. 257p.

BOTTENTUIT JUNIOR, João Batista; COUTINHO, Clara Pereira. Recomendações de qualidade para o processo de avaliação de WebQuests. Ciênc. cogn. [online]., v. 17, n. 1, p. 73-82, 2012.

BRITO, Kalina Lígia Almeida; HAERTEL, Brigitte Úrsula Stach. Metodologias Ativas e os Jogos no Ensino e Aprendizagem da Matemática. In: PBL2018 International Conference, Anais do Congresso: ABP para Próxima Geração, Articulando Aprendizagem Ativa, Tecnologia e Justiça Social. Santa Clara Califórnia - USA, 2018.

CARVALHO, Ana Amélia Amorim. WebQuest: um desafio aos professores para os alunos. 2002. Disponível em: http://www.iep.uminho.pt/aac/diversos/webquest/index.htm. Acesso em: 20 out. 2021.

CLAUDIO, Nuria Zarco; MACHANCOSES, Mónica; PIQUERAS, Rocío Fernández. La Eficacia de La Escape Room Como Estrategia de Motivación, Cohesión y Aprendizaje de Matemáticas En Sexto de Educación Primaria. Edetania, [s. I], p. 23-42, 8 dez. 2019.

COSTA, Isabel Maria de Sousa. A WebQuest na Aula de Matemática: um estudo de caso com alunos do $10^{\circ}$ ano de escolaridade. Dissertação de Mestrado em Educação com Especialização em Tecnologia Educativa. Braga: Universidade do Minho, Instituto de Educação e Psicologia, 2008.

CRUZ, Ivete Liliana Malheiro da. A WebQuest na sala de aula de Matemática: um estudo sobre a aprendizagem dos Lugares Geométricos por alunos do $8^{\circ}$ ano. Dissertação de Mestrado em Educação, na área de especialização em Supervisão Pedagógica de Ensino de Matemática, Braga: Universidade do Minho, 2006.

DODGE, Bernie. Some Thoughts about WebQuests. 1995. Disponível em: http://WebQuest.sdsu.edu/about_WebQuests.html. Acesso em: 07 jan. 2021. 
FERNANDES, Clarice Silva. Uso de Recursos da Internet para o ensino de Matemática: WebQuest uma experiência com professores do ensino médio. Dissertação de Mestrado em Educação Matemática. São Paulo: Pontifícia Universidade Católica de São Paulo, 2008.

FERREIRA JUNIOR, Herbert Hipólito. Escape Matemático: Jogo de conteúdos matemáticos, enigmas, charadas e truques de raciocínio lógico. 2019. Dissertação (Mestrado) - Curso de Matemática em Rede Nacional (Profmat), Instituto de Ciência e Tecnologia, Universidade Federal de São Paulo, São Paulo, 2019. 39p.

GUIMARÃES, Daniela. A Utilização da WebQuest no Ensino da Matemática: aprendizagem e reações dos alunos do $8^{\circ}$ ano. 2005. Dissertação (Mestrado em Educação) - Universidade do Minho, Portugal, 2005. 202p.

JIMÉNEZ, Cristina et al. Digital Escape Room, Using Genial.Ly and A Breakout to Learn Algebra at Secondary Education Level in Spain. Education Sciences, [S.L.], v. 10, n. 10, p. 271, 1 out. 2020. Disponível em: https://www.mdpi.com/845484. Acesso em: 18 nov. 2021.

MACEDO, Kelly Dandara da Silva et al. Metodologias ativas de aprendizagem: caminhos possíveis para inovação no ensino em saúde. Escola Anna Nery. Revista de Enfermagem, v. 22, p. 1, 2018.

MENDES, Daniela. Criando uma Escape Room com o Google Forms! Crie uma história e engaje seus alunos com Matemática! Rede Laboratório sustentável de matemática, [201-]. Disponível em: https://www.laboratoriosustentaveldematematica.com/2020/08/criando-um-escape-room-com-ogoogle.html. Acesso em: 7 jan. 2022.

MONTEIRO JUNIOR, Luis Americo; REIS, Luiza Sandim. O Lúdico na Matemática por Meio de Jogos e de um Escape Room. In: Seminário de Iniciação Científica do Litoral Norte - SIC-LN, Caraguatatuba. Apresentações - Seminário de Iniciação Científica do Litoral Norte - SIC-LN, 2020.

MORAN, José. Educação Híbrida: um conceito chave para a educação, hoje. In: BACHIC, L.; TANZI NETO, A.; TREVISANI, F. M. (org.). Ensino Híbrido: personalização e tecnologias na educação. Porto Alegre: Penso, 2015. p. 27-45.

MOURA, Adelina; SANTOS, Idalina Lourido. Escape Room Educativo: reinventar ambientes de aprendizagem. In: CARVALHO, A. A. A. (org.). Aplicações para dispositivos móveis e estratégias inovadoras na educação. Lisboa: Ministério da Educação Direção Geral da Educação, 2020. p. 107115.

OCDE. Compétences en sciences, lecture et mathématiques: le cadre d'évaluation de PISA 2006. Paris: OCDE, 2006.

OTEMAIER, Kelly R. et al. Educational escape room for teaching Mathematical Logic in computer courses. In: XIX Brazilian Symposium on Computer Games and Digital Entertainment, 2020, Recife PE. SBC - Proceedings of SBGames 2020, 2020. p. 595-604.

QUADROS, Lídia. A Utilização de uma Webquest no Desenvolvimento do Pensamento Crítico e Criativo na Disciplina de Matemática. 2005. Dissertação (Mestrado em Educação) - Faculdade de Psicologia e Ciências da Educação, Lisboa, 2005. 168p. 
REZENDE, Felipe Augusto de Mello; MARTINS, Laiane Pereira; OLIVEIRA, Mariana Fonseca. O suspeito-escape room para discutir questões sociais e avaliar a aprendizagem de estudantes da educação básica. Revista Eletrônica Ludus Scientiae, Foz do Iguaçu, v. 4, n. 2, p. 105-122, 2020.

RIBACIONKA, Márcia Cristina dos Santos. Uma proposta de WebQuest para a introdução ao letramento estatístico dos alunos da E.J.A. 2010. Dissertação (Mestrado em Educação) - Pontifícia Universidade Católica de São Paulo, São Paulo, 2010. 218p.

RODRIGUES, Suênia da Silva et al. A Webquest como proposta Metodológica para o Ensino de Matemática. In: II Congresso Nacional de Educação (II CONEDU), 2015, Campina Grande. Anais II CONEDU, 2015. v. 1.

ROTHER, Francisco. Metodologias Ativas Aplicadas no Processo de Ensino Aprendizagem da Matemática. 2016. TCC (Graduação em Matemática). Curso de Matemática, Faculdades de Itapiranga, Itapiranga, 2016. 14p.

SAMPAIO, Patrícia. Concepção de Infinito dos Alunos do Ensino Secundário: contributo da Webquest Echer e a procura do infinito. 2006. 246 f. Dissertação (Mestrado em Educação). Universidade do Minho, Braga, 2006.

SANTIAGO, E. G. L. O Uso de Ferramenta Webquest e sua Implicação em Atividades Didáticas Experimentais para a Melhoria do Ensino da Matemática. 2008. 132 f. Dissertação (Mestrado em Educação) - Universidade Federal do Rio Grande do Sul, Porto Alegre, 2008.

SEGURA-ROBLES, Adrián; PARRA-GONZÁLEZ, María Elena. How to implement active methodologies in Physical Education: Escape Room. ESHPA - Education, Sport, Health and Physical Activity, v. 3, n. 2, p. 295-306, 2019. DOI http://hdl.handle.net/10481/56426.

SIERRA DAZA, María Caridad; FERNÁNDEZ-SÁNCHEZ, María Rosa. Gamificando a sala de aula da universidade. Análise de uma experiência de Escape Room no ensino superior. Revista de estudos e experiências em educação, v. 18, n. 36, p. 105-115, 2019. Disponível em: https://scielo.conicyt.cl/scielo.php?pid=S0718-51622019000100105\&script=sci_arttext\&tlng=n. Acesso em: 8 nov. 2021.

SILVA, Maurício Barbosa da. A Geometria espacial no ensino médio a partir da atividade de WebQuest: análise de uma experiência. Dissertação de Mestrado em Educação Matemática São Paulo: Pontifícia Universidade Católica de São Paulo. 2006.

STOHLMANN, Micah S. Escape Room Math: Luna's Lines. Professor de Matemática: Aprendizagem e Ensino PK-12, v. 113, n. 5, p. 383-389, 2020. DOI http://dx.doi.org/10.5951/mtlt.2019.0106.

TURCI, Bruno de Moraes. Um estudo sobre o uso de WebQuests para revisar conteúdos matemáticos. 2015. Dissertação (Mestrado em Mestrado Profissional em Matemática em Rede Nacional) - Instituto de Ciências Matemáticas e de Computação, Universidade de São Paulo, São Carlos, 2015. DOI 10.11606/D.55.2015.tde-01122015-140605.

VELDKAMP, Alice et al. Escape education: a systematic review on escape rooms in education. Educational Research Review, [S.I.], v. 31, p. 100364, nov. 2020. DOI http://dx.doi.org/10.1016/j.edurev.2020.100364. 
VISEU, A. Uma Pesquisa Voltada a Geometria Espacial no Ensino Médio a Partir da Atividade Motivacional Webquest: análise de uma experiência. 2014. Dissertação (Mestrado em Educação). Pontifícia Universidade Católica de São Paulo, São Paulo, 2014. 155p.

WEBQUEST EDO APLICADA. EDO: Equações Diferenciais Ordinárias. Juros Continuamente Compostos. Licenciatura em Matemática - 1 Ciclo - 2012. Sites Google, 2012. Disponível em:

https://sites.google.com/site/webquestedoaplicada/. Acesso em: 7 jan. 2022.

WEBQUEST ESTATÍSTICA. Introdução. Sites Google, [201-]. Disponível em:

https://sites.google.com/view/webqestatistica/tarefa. Acesso em: 7 jan. 2022.

XAVIER, T. J. Análise de Webquests dos $2^{\circ}$ e $3^{\circ}$ Ciclos do Ensino Básico: um estudo exploratório da disciplina matemática. 2007. Dissertação (Mestrado em Educação). Universidade do Minho, Braga, 2007. 233p. 